\title{
Two-Dimensional versus Three-Dimensional Transabdominal Sonography for Measurement of Lower Uterine Segment Thickness in Women at Term Pregnancies with Previous Caesarean Sections
}

\author{
ABD ELMONEM M. ZKARIA, M.D.; ABD ELMONSEF A. SEDEK, M.D. and \\ MOHAMMED Sh. ABD EL-MOHSEN MOSTAFA, M.Sc. \\ The Department of Obstetrics and Gynaecology, Faculty of Medicine, Al-Azhar University
}

\begin{abstract}
Background: Caesarean section is the commonest operation performed by the gynecologists and due to the risks and benefits of ERC and VBAC, cases selection and counseling are of out most importance.

Aim of Study: To evaluate inter method and inter observer reliability of $2 \mathrm{D}$ versus $3 \mathrm{D}$ trans abdominal sonography for lower uterine segment measurement.

Method: The study enrolled 100 pregnant women under going elective lower uterine segment caesarean section, all sonographic examination was performed by an ultrasound Voluson E6 BT16 Transducer for 2D and 3D trans abdominal sonography, inner myometrial thickness and full thickness will be measured at the thinnest portion and perpendicular to the contour of the lower uterine segment, then measurement intra operatively using graduated sound.

Results: Lower uterine segment inner and full diameter measurements were strongly and directly correlated by both 2D and 3D ultrasonography which means the 3D method of assessment added no more value. Both 2D and 3D method of assessment were correlated to a lower uterine segment measurement intra operatively with a comparable correlation factor.

Conclusion: Multiple caesarean section patients had a significant lower value of lower uterine segment thickness by all means of measurements.
\end{abstract}

Key Words: Lower uterine segment thickness - Previous caesarean section.

\section{Introduction}

CAESAREAN section is the commonest operation performed by the gynecologists and one of the commonest surgical procedures in general. The rates of Caesarean section are continuing to rise all over the world [1].

Correspondence to: Dr. Mohammed Sh. Abd El-Mohsen Mostafa, E-Mail: alhemzawy@gmail.com
For women who have had previous Caesarean section, choices for mode of birth in their next pregnancy are either trial of vaginal birth after caesarean (VBAC) or an elective repeat caesarean (ERC). Caesarean section is associated with complications in subsequent pregnancies, such as placenta previa, placenta accreta, increta or percreta 1 dehiscence or uterine rupture. Also the surgical maternal morbidity including risk of bowel and bladder injury is significantly increased [2].

In the recent years vaginal birth after Caesarean (VBAC) was found to be less safe than was thought previously. This fact led to less obstetricians offering and less patients accepting VBAC. Decreased utilization of VBAC and increased rates of ERC is one of the major factors behind global increase in Caesarean section rates [3].

According to the available evidence, VBAC is associated with increased risk of maternal hemorrhage, blood transfusion, peripartum hysterectomy and uterine rupture. Fetal risks of VBAC includes Hypoxic Ischemic Encephalopathy and stillbirth. However, the absolute risk of all previously mentioned adverse events is still low and the success rate of VBAC is estimated to be $72-76 \%$ in most of studies [4].

Uterine rupture due to dehiscence of the previous C.S scar is one of the most morbid and catastrophic complications that may happen with VBAC trial. The risk of uterine rupture during VBAC trial is estimated to be 74/10000 [5].

Many authors have tried to predict the possibility of scar dehiscence and uterine rupture in patients candidate for VBAC. Prediction of scar dehiscence 
will help in patient selection for VBAC. Trails have been made to visualize the lower uterine segment (LUS) and previous C.S scar. Many methods have been suggested, including Hysterography, sono hysterography, hysteroscopy, magnetic resonance imaging and ultra sonography [6].

The role of ultrasound in visualization of the lower uterine segment and detection of C.S scar defects has been investigated by many authors. Two dimensional (2-D) transvaginal ultrasound was found to be an accurate method for measurement of scar thickness. The addition of saline sonohysterography can improve the demarcation of the scar [2].

Many authors have tried to utilize transabdominal and transvaginal 2-D ultrasound to measure the scar thickness and detect the healing defects. Some authors measured the entire thickness of the lower uterine segment [7], while others measured the muscular layer thickness [8]. The optimal cutoff value predicting scar dehiscence varied from 2.0 to $3.5 \mathrm{~mm}$ for full LUS thickness and from 1.4 to 2.0 for myometrial layer [6].

Three dimensional ultrasound gets more and more applications in the field of obstetrics and gynaecology. One of the main advantages of 3-D ultrasound is the ability to reconstruct and display any arbitrarily chosen section within the volume dataset. Many of these planes cannot be obtained on conventional two dimensional sonography, as a result of the restrictions on probe movements during examination imposed by pelvic anatomy [9].

The use of three dimensional ultrasound in visualizing LUS and measuring Caesarean scar thickness has started to be investigated recently. Martins and co-workers in 2009 [12] have suggested that 3-D ultrasound decrease the inter observer variability in sonographic measurement of scar thickness, making the use of ultrasound for this goal more accurate. However, Cheung et al. [22], have reached different conclusion as 3D in comparison to 2-D transabdominal approach did not seem to improve the reliability of LUS thickness measurement.

Uterine rupture is an uncommon complication of vaginal birth after caesarean (VBAC), the maternal and fetal consequences of which can be serious and potentially life threatening [10,11]. At present there are no reliable methods for predicting the risk of uterine rupture in women attempting VBAC. Some authors have suggested that sonographic measurement of the lower uterine segment
(LUS) may help to select women with the lowest risk of uterine rupture during labor [6,7]. Although it has been shown that the risk of a scar defect is inversely correlated with LUS thickness, the technique of this measurement remain controversial $[\mathbf{6 , 7 , 8 ]}$. In a recent systemic review of 12 studies involving 1834 women, Jastrow et al. (2010), [6] confirmed that women with uterine defects had thinner LUS than those without defects. of the the 12 studies included in the review, 7 measured the full LUS thickness, 4 measured the myometrial layer only, and one measured both. However, owing to the heterogeneity of the studies, no ideal cutoff for lower uterine thickness could be recommended for clinical purposes, and the optimal cutoff value varied from 2 to $3 \mathrm{~mm}$ for the full LUS thickness and from 1.4 to $2 \mathrm{~mm}$ for the myometrial layer [6].

The introduction of 3D volume sonography has enabled multiplanar display of 3D images of LUS, which potentially can improve the reliability of lower uterine segment measurement. One of the best uses of 3D ultra sound is in finding the true center of an object of interest; thus, it could theoretically locate the thinnest area in the US. Inter method and inter observer reliability are important when evaluating a clinical test because they ensure reliable measurements when made via another technique or observer, respectively. Previously, only one study addressed the reliability of LUS measurement using 2D and 3D approaches [12]. However that study did not assess the inter method reliability of lower uterine segment measurement using 3D sonography compared with the $2 \mathrm{D}$ approach.

\section{Aim of the work:}

The objective of the present study is to evaluate inter method and inter observer reliability of 2D versus $3 \mathrm{D}$ transabdominal sonography for lower uterine segment measurement.

\section{Patients and Methods}

Our study was conducted around the year and enrolled 100 pregnant women presented to Obstetric and Gynecology Department, Al-Azhar University, Cairo undergoing elective lower uterine segment caesarean section in the period between 7/2019 to $7 / 2020$.

The studied population was divided into 2 groups for analysis: Group I: 50 cases with one previous section. Group II: 50 cases with more than one previous section. 
Both groups met the inclusion and avoided the following exclusion criteria:

Inclusion criteria: Any patient with previous caesarean section and full term at 36-39 weeks of pregnancy. Patient undergoing elective caesarean section.

Exclusion criteria: The women are in labor at the time of ultrasound examination. Women with multiple gestation. Abnormal amniotic fluid volume. Placenta previa.

After agreement of the ethical committee and informed written consent were obtained; complete history taking and clinical examination were done. Routine pre-operative laboratory profile was assessed.

All sonographic examination were performed with an ultrasound machine Voluson E6 BT16 equipped with a 4-8-MHz transducer for $2 \mathrm{D}(\mathrm{C} 1-$ 5-D) and 3D (RAB-6-D) volume scanning.

All participants were assessed for lower uterine segment measurement via 2D and 3D trans abdominal sonography. The 3D examination was performed on the multi planar display of the longitudinally acquired LUS volume.

Inner myometrial thickness (MT) and full thickness (FT) were measured at the thinnest portion and perpendicular to the contour of the lower uterine segment.

The lower uterine segment were visualized in sagittal section in the midline.

Intra operatively; as a gold standard uterine scar thickness was measured using a graduated sound during elective caesarean section after delivery of the fetus.

Data analysis were conducted to compare the diagnostic accuracy and reliability of $2 \mathrm{D}$ versus 3D trans abdominal ultrasound in assessment of caesarean section scar and to correlate them for the intra operative values.

Other univariates were assessed to validate whether the number of caesarean section scars could affect integrity if more than one caesarean section.

\section{Statistical analysis:}

Data were collected, revised, coded and entered to the statistical package for social science version 17 and the following were done.
Qualitative data were presented as number and percentages and comparison between two groups with qualitative data were done by using Chisquare test.

Quantitative data were presented as mean, standard deviations and ranges and comparison between two groups with quantitative data were done by using Independent $t$-test.

Pearson correlation coefficients was used to assess the relation between two quantitative parameters.

Receiver operating curve (ROC) was used to assign a cut off value of a test quantitative variable for prediction of a state of a nominal one with estimation of area under the curve AUC, sensitivity and specificity.

The p-value was considered significant as the following: $p>0.05$ : Non significant. $p<0.05$ : Significant. $p<0.01$ : Highly significant.

\section{Results}

Our study enrolled 100 pregnant females during their follow-up till labor. The mean age was $30.65 \pm$ 4.9 years with minimal age of 19 years and maximal age of 38 years with mean gestational age (GA) of $37 \pm 1.4$ weeks as shown in Table (1).

Table (1): The mean of age and gestational age of patients.

\begin{tabular}{lccccc} 
& N Minimum & Maximum & Mean & $\begin{array}{c}\text { Std. } \\
\text { Deviation }\end{array}$ \\
\hline Age & 100 & 19.00 & 38.00 & 30.6500 & 4.91416 \\
$\begin{array}{l}\text { Gestational } \\
\text { age }\end{array}$ & 100 & 36.00 & 40.00 & 37.7900 & 1.43051 \\
\hline
\end{tabular}

The means of gravida $(\mathrm{G})$, para $(\mathrm{P})$, abortions (A) and livebirth (L) are illustrated in Table (2) and Fig. (1).

Table (2): The means of gravida, para, abortion and live births of patients.

\begin{tabular}{cccccc}
\hline & $\mathrm{N}$ & Minimum & Maximum & Mean & $\begin{array}{c}\text { Std. } \\
\text { Deviation }\end{array}$ \\
\hline $\mathrm{G}$ & 100 & 2.00 & 7.00 & 4.3600 & 1.25947 \\
$\mathrm{P}$ & 100 & 1.00 & 5.00 & 2.8300 & 1.32615 \\
$\mathrm{~A}$ & 100 & 0.00 & 2.00 & 0.5200 & 0.59425 \\
$\mathrm{~L}$ & 100 & 1.00 & 5.00 & 2.8700 & 1.34581 \\
\hline
\end{tabular}




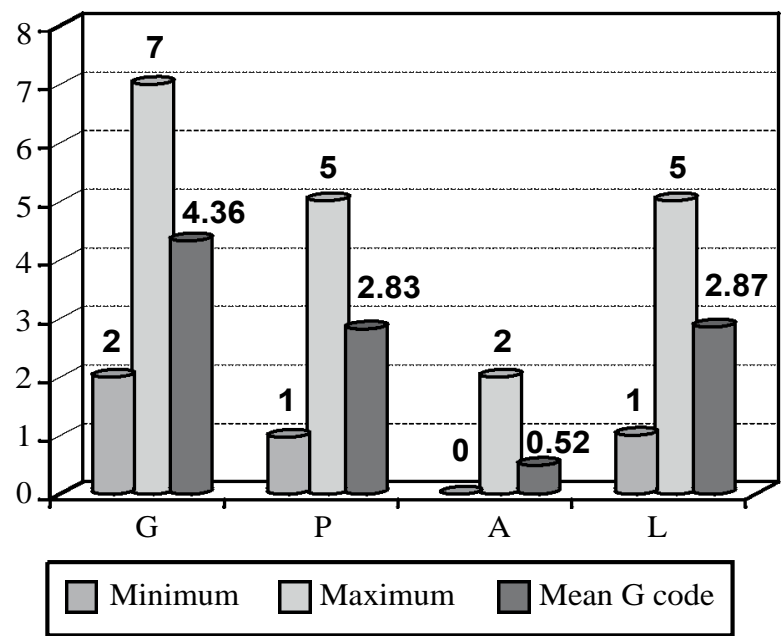

Fig. (1): The means of gravida, para, abortion and live births of patients.

The mean values of uterine wall thicknesses as measured by all methods are shown in Table (3) and Fig. (2).

Table (3): The mean values of uterine wall thickness as measured by all methods.

\begin{tabular}{lccccc}
\hline \multicolumn{7}{c}{ N Minimum Maximum Mean } & $\begin{array}{c}\text { Std. } \\
\text { Deviation }\end{array}$ \\
\hline Inner2D & 100 & 1.00 & 5.30 & 2.7990 & 1.01459 \\
Full2D & 100 & 2.00 & 8.00 & 4.8280 & 1.41736 \\
Inner3D & 100 & 1.20 & 6.00 & 2.9880 & .96497 \\
Full3D & 100 & 2.00 & 7.00 & 4.9440 & 1.30673 \\
Intraop. & 100 & 2.00 & 8.00 & 5.4500 & 1.50336 \\
Thickness & & & & & \\
\hline
\end{tabular}
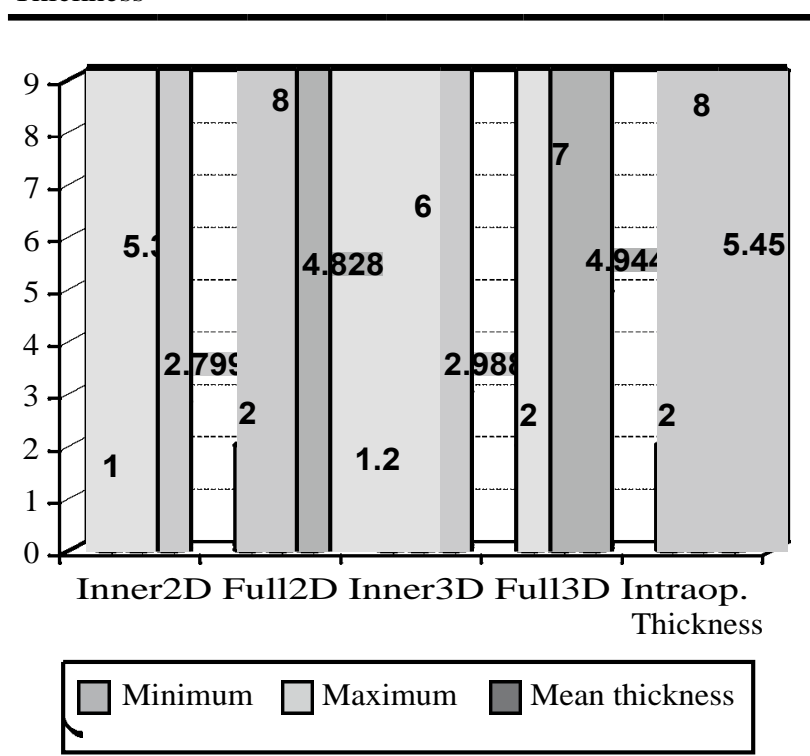

Fig. (2): The mean values of uterine wall thickness as measured by all methods.

\section{Habits of medical importance:}

Only $3 \%$ of the enrolled population were active smokers during pregnancy as shown in Table (4) and Fig. (3).
Table (4): Percentage of smokers between the patients.

\begin{tabular}{lcc}
\hline & Frequency & Percent \\
\hline Non smokers & 97 & 97.0 \\
Smokers & 3 & 3.0 \\
\hline Total & 100 & 100.0 \\
\hline
\end{tabular}

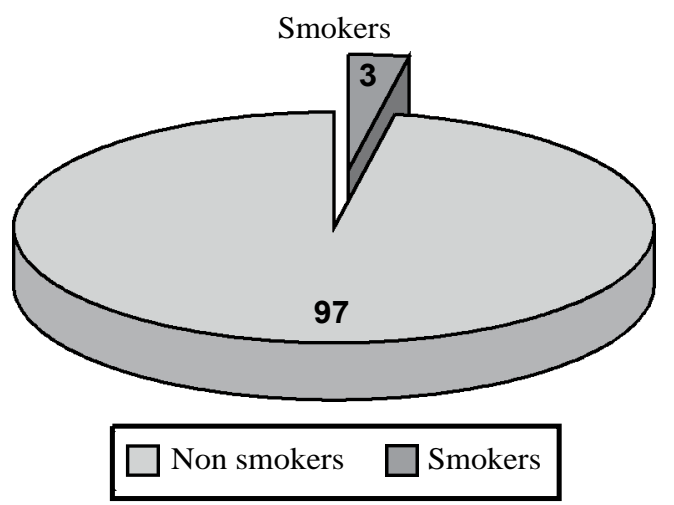

Fig. (3): Percentage of smokers between the patients.

\section{Gestational HTN:}

Eight percentage of enrolled female developed gestational HTN as shown in Table (5) and Fig. (4).

Table (5): Percentage of patients that have gestational hypertension.

\begin{tabular}{lcc} 
& Frequency & Percent \\
No Gestational HTN & 92 & 92.0 \\
Gestational HTN & 8 & 8.0 \\
\hline Total & 100 & 100.0 \\
\hline
\end{tabular}

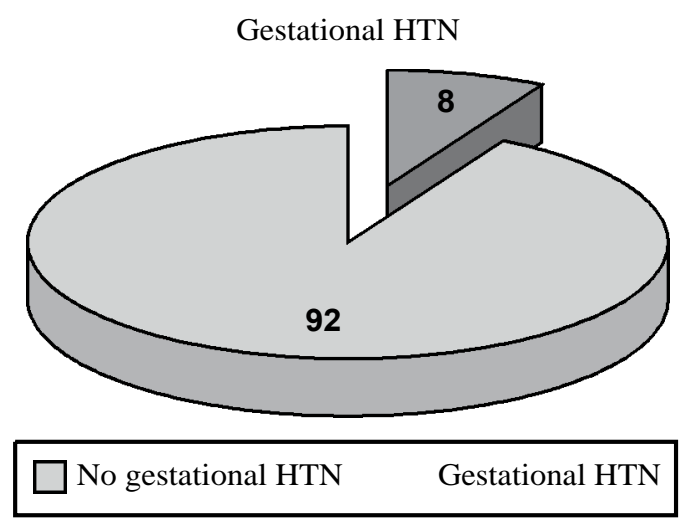

Fig. (4): Percentage of patients that have gestational hypertension.

\section{Gestational diabetes mellitus:}

Five percentage of studied women had gestational diabetes as shown in Table (6) and Fig. (5). 
Table (6): Percentage of patients that have gestational diabetes mellitus.

\begin{tabular}{lcc}
\hline & Frequency & Percent \\
\hline No Gestational Diabetes & 95 & 95.0 \\
Gestational Diabetes & 5 & 5.0 \\
\hline Total & 100 & 100.0 \\
\hline
\end{tabular}

Gestational Diabetes

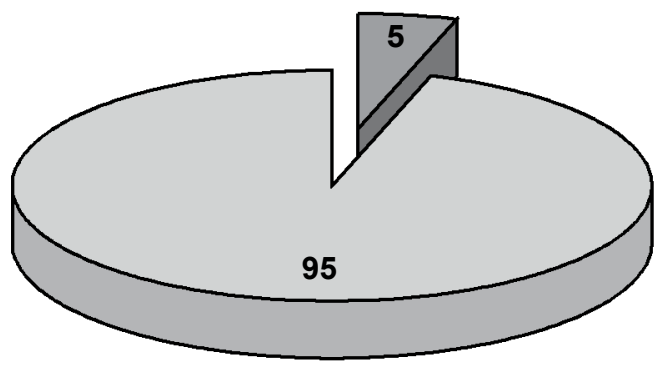

$\square$ No Gestational Diabetes $\square$ Gestational Diabetes

Fig. (5): Percentage of patients that have gestational diabetes mellitus.

The studied population were divided into two groups according to the number of CS for comparison:

- Group I (50 patients): Only one CS.

- Group II (50 patients): More than one CS.

Univariate comparative analysis between the two groups:

Age:

Patients of group II had a significantly older age as expected than group I as shown in Table (7) and Fig. (6) as $p$-value was 0.0001.

Table (7): Comparative analysis between two groups as regard age.

\begin{tabular}{ccccc}
\hline & Number cs & \multicolumn{4}{l}{ N Mean Std. Deviation } & $p$ \\
\hline Age & 1 & 5028.4400 & 5.36489 & 0.0001 \\
& 2 & 5032.8600 & 3.16879 & \\
\hline
\end{tabular}

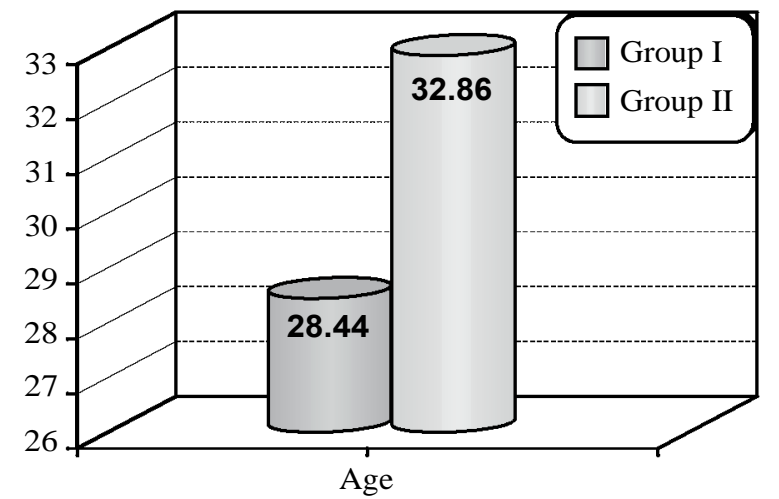

Fig. (6): Comparative analysis between two groups as regard age.

\section{Gestational age:}

Group II had a significantly higher gestational age than group I as shown in Table (8) and Fig. (7) with $p$-value 0.0001 .

Table (8): Comparative analysis between two groups as regard gestational age.

\begin{tabular}{llllcc}
\hline & Number cs & N Mean & $\begin{array}{c}\text { Std. } \\
\text { Deviation }\end{array}$ & $p$ \\
\hline Gestational & Group I & 50 & 36.6400 & .66271 & 0.0001 \\
age & Group II & 50 & 38.9400 & .99816 & \\
\hline
\end{tabular}

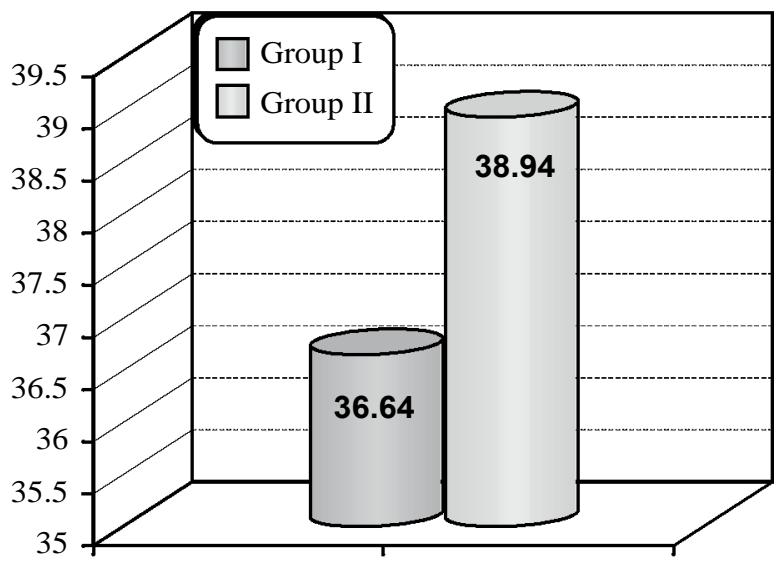

Gestational age

Fig. (7): Comparative analysis between two groups as regard gestational age.

\section{Gestational state:}

A significantly higher gestational parameters for $\mathrm{G}, \mathrm{P}$, Abortions and live births were witnessed in Group II as compared to group I as seen in Table (9) and Fig. (8).

Table (9): Comparative analysis between two groups as regard gravida, para, abortions and live births.

\begin{tabular}{llcccc}
\hline & & $\mathrm{N}$ & Mean & $\begin{array}{c}\text { Std. } \\
\text { Deviation }\end{array}$ & $p$ \\
\hline $\mathrm{G}$ & Group I & 50 & 3.6400 & 1.12050 & 0.0001 \\
& Group II & 50 & 5.0800 & .94415 & \\
$\mathrm{P}$ & Group I & 50 & 2.1800 & 1.10083 & 0.0001 \\
& Group II & 50 & 3.4800 & 1.21622 & \\
$\mathrm{~A}$ & Group I & 50 & .4000 & .57143 & 0.043 \\
& Group II & 50 & .6400 & .59796 & \\
$\mathrm{~L}$ & Group I & 50 & 2.2200 & 1.14802 & 0.0001 \\
& Group II & 50 & 3.5200 & 1.21622 & \\
\hline
\end{tabular}




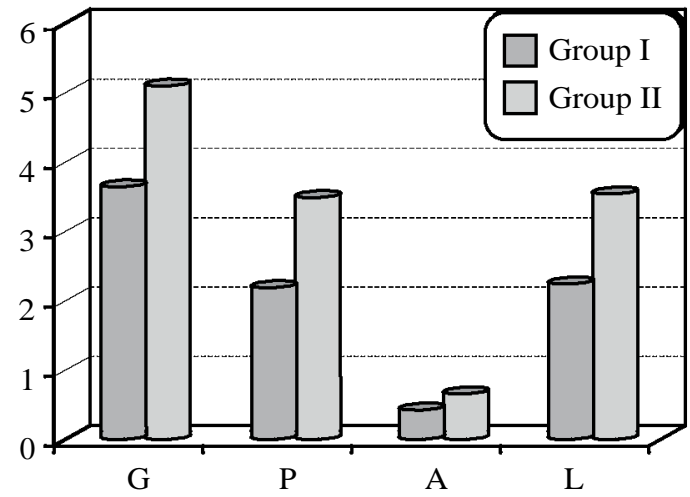

Fig. (8): Comparative analysis between two groups as regard gravida, para, abortions and live births.

Anterior wall thickness:

A significantly thinner anterior wall thickness in group II as measured by all means of 2D, 3D and intraoperative than group I as shown in Table (10) and Fig. (9).

Table (10): Comparative analysis between two groups as regard thickness of anterior wall measured by 2D, 3D and intra operative measurements.

\begin{tabular}{llllll}
\hline & Number cs & $\mathrm{N}$ & Mean & $\begin{array}{c}\text { Std. } \\
\text { Deviation }\end{array}$ & $p$ \\
\hline Inner2D & Group I & 50 & 3.3760 & .93275 & 0.0001 \\
& Group II & 50 & 2.2220 & .72823 & \\
Full2D & Group I & 50 & 5.9260 & .67938 & 0.0001 \\
& Group II & 50 & 3.7300 & 1.06623 & \\
Inner3D & Group I & 50 & 3.4820 & .92310 & 0.0001 \\
& Group II & 50 & 2.4940 & .72883 & \\
Full3D & Group I & 50 & 5.9320 & .43445 & 0.0001 \\
& Group II & 50 & 3.9560 & 1.12652 & \\
Intraop. & Group I & 50 & 6.5800 & .59213 & 0.0001 \\
Thickness & Group II & 50 & 4.3200 & 1.26878 & \\
\hline
\end{tabular}

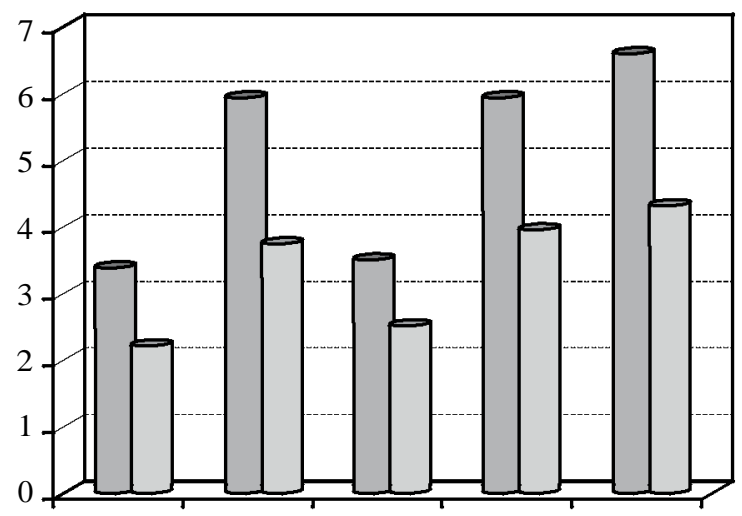

Inner2D Full2D Inner3D Full3D Intraop.

Thickness

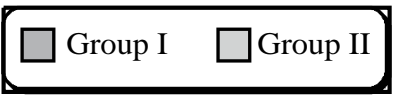

Fig. (9): Comparative analysis between two groups as regard thickness of anterior wall measured by 2D, 3D and intra operative measurements.
As regard to smoking and gestational HTN, DM there were insignificant difference between the two groups as shown in Table (11).

Table (11): Differences between two groups as regard to smoking, gestational hypertension and gestational diabetes mellitus.

\begin{tabular}{lccc}
\hline & Group I & Group II & $p$-value \\
\hline Smoking & $0 / 50$ & $3 / 50$ & 0.24 \\
Gestational HTN & $2 / 50$ & $6 / 50$ & 0.27 \\
Gestational DM & $3 / 50$ & $2 / 50$ & 1 \\
\hline
\end{tabular}

Correlation between anterior wall thickness measurements by different methods:

Inner $2 D$ versus Inner $3 D$ :

There was a strong significant positive correlation between the two methods for measurement as $\mathrm{R}$ was 0.96 and $p$-value was 0.0001 as shown in Fig. (10).

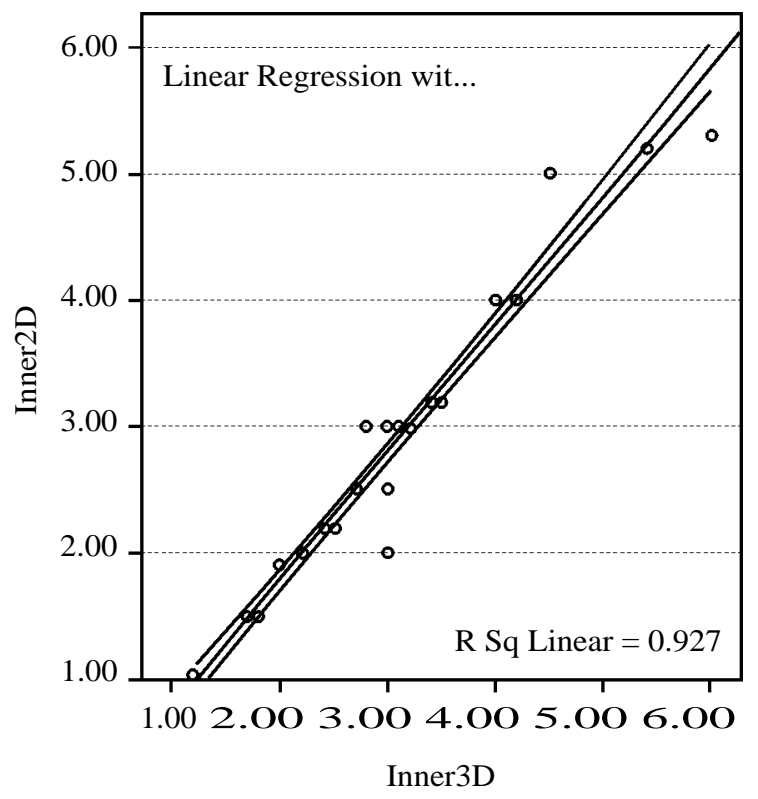

Fig. (10): Correlation between anterior wall thickness measurements by (inner 2D versus inner 3D).

\section{Inner $2 D$ and intraoperative method:}

There was a strong significant positive correlation between the two methods for measurement as $\mathrm{R}$ was 0.82 and $p$-value was 0.0001 as shown in Fig. (11). 


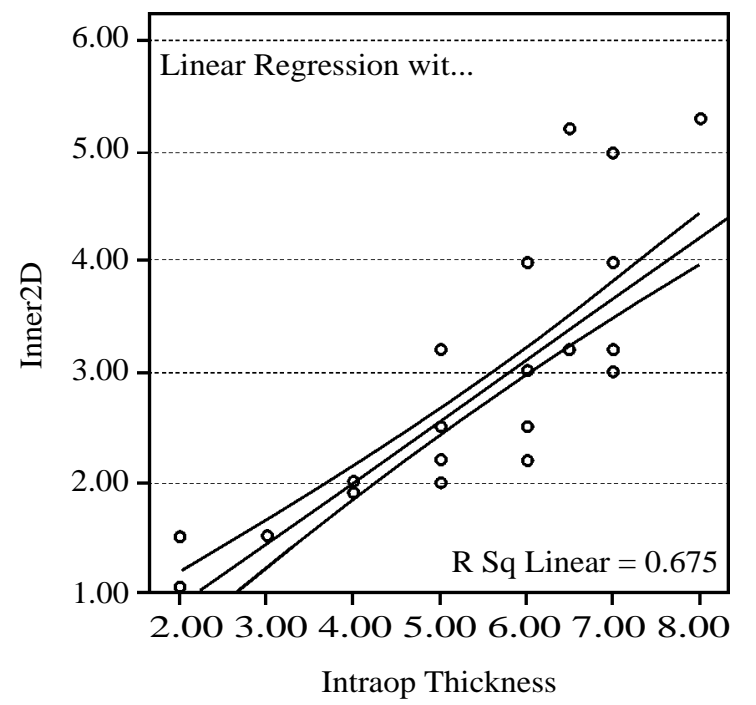

Fig. (11): Correlation between anterior wall thickness measurements by (inner 2D and intra operative method).

Inner $3 D$ and intraoperative method:

There was a strong significant positive correlation between the two methods for measurement as $\mathrm{R}$ was 0.822 and $p$-value was 0.0001 as shown in Fig. (12).

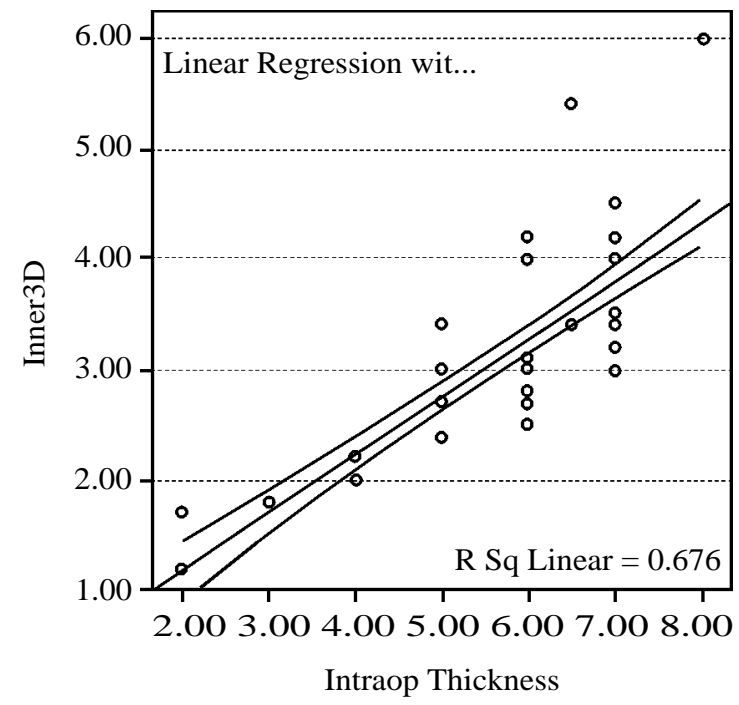

Fig. (12): Correlation between anterior wall thickness measurements by (inner 3D and intra operative method).

\section{Full $2 D$ and Full $3 D$ :}

There was a strong significant positive correlation between the two methods for measurement as $\mathrm{R}$ was 0.97 and $p$-value was 0.0001 as shown in Fig. (13).

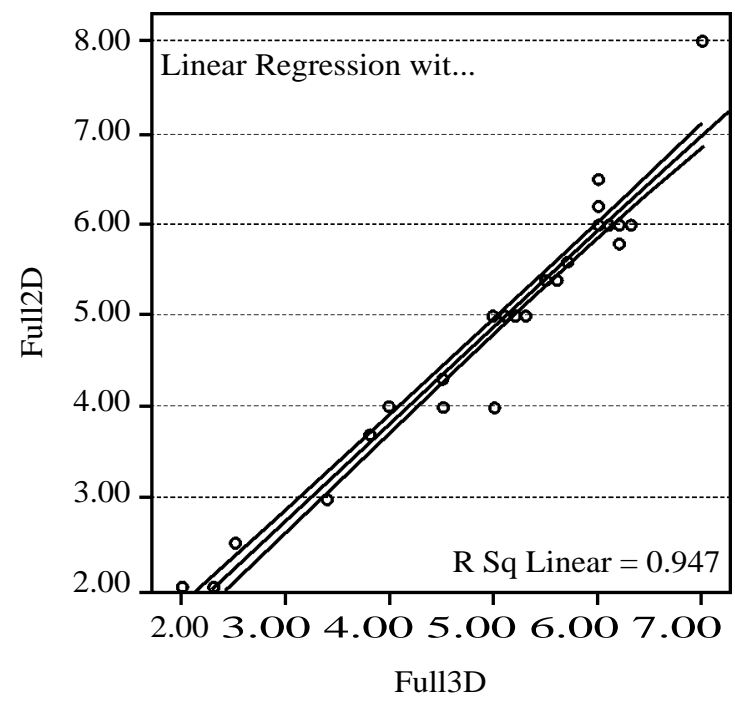

Fig. (13): Correlation between anterior wall thickness measurements by different method (full 2D and full 3D).

\section{Full 2D and intraoperative method:}

There was a strong significant positive correlation between the two methods for measurement as $\mathrm{R}$ was 0.97 and $p$-value was 0.0001 as shown in Fig. (14).

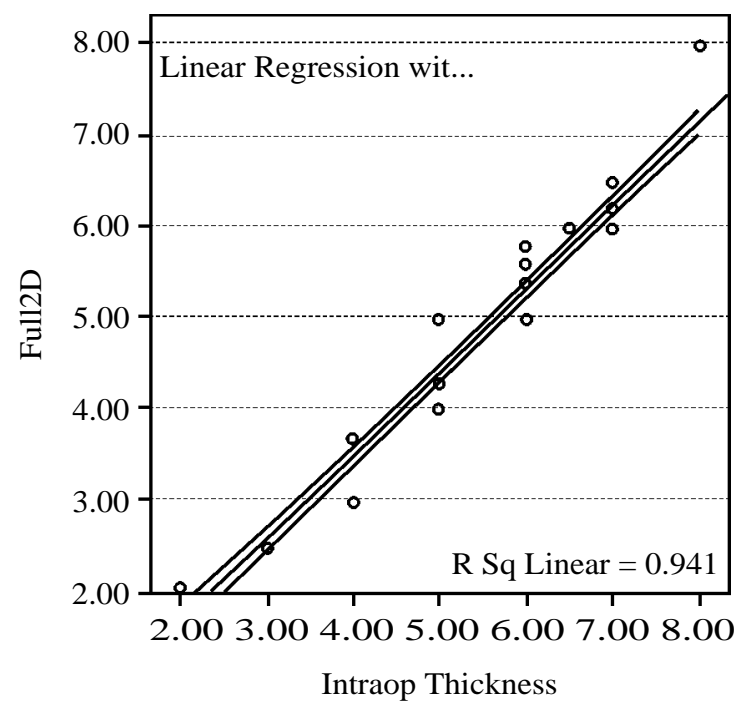

Fig. (14): Correlation between anterior wall thickness measurements by different method (full 2D and intra operative method).

\section{Full $3 D$ and intraoperative method:}

There was a strong significant positive correlation between the two methods for measurement as $\mathrm{R}$ was 0.97 and $p$-value was 0.0001 as shown in Fig. (15). 


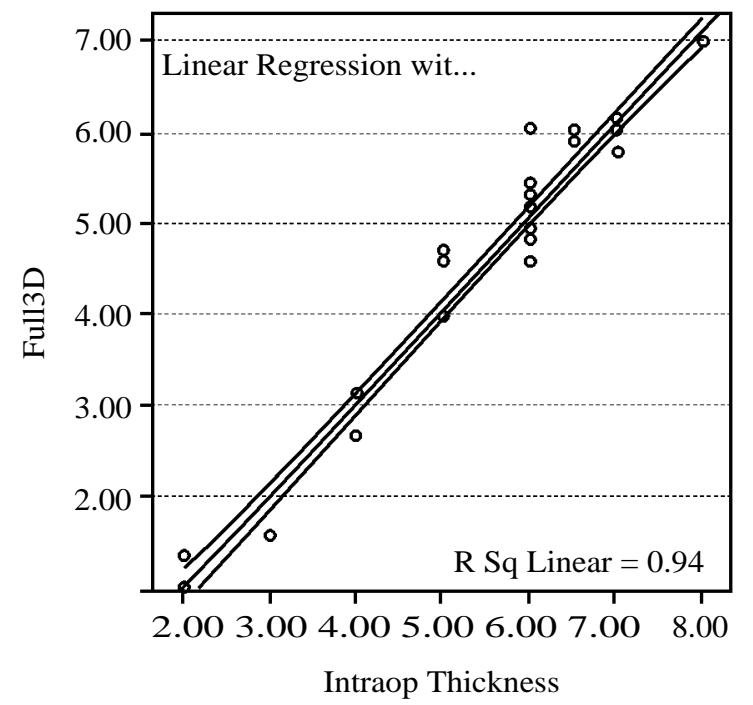

Fig. (15): Correlation between anterior wall thickness measurements by (full 3D and intra operative method).

Correlation between intraoperative uterine wall thickness measurement and the age:

The correlation between intraoperative uterine wall thickness measurement and the age was inversely and statistically significant when correlated to age as $\mathrm{R}$ was -0.36 and $p$-value was 0.0001 as shown in Fig. (16).

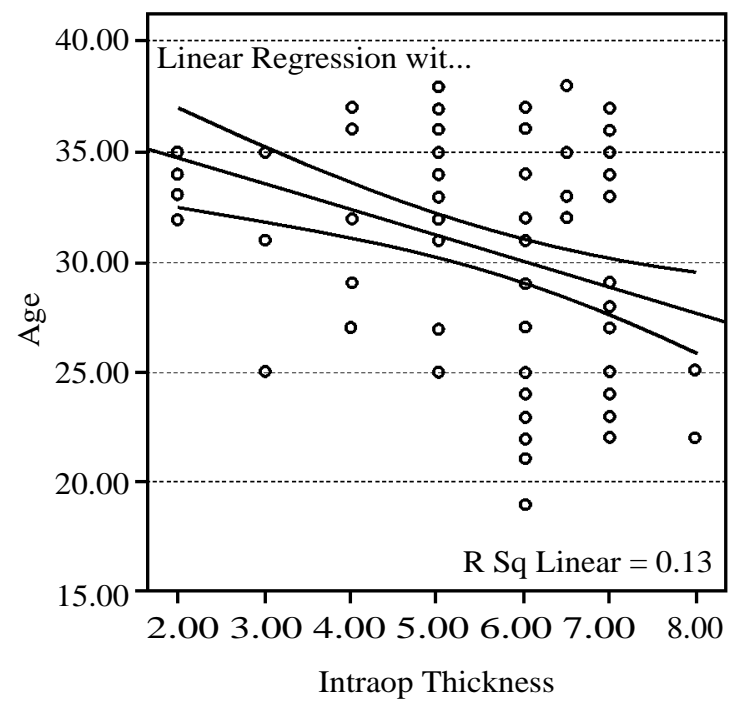

Fig. (16): Correlation between intraoperative uterine wall thickness measurement and the age.

Correlation between intraoperative uterine wall thickness measurement and the frequency of gravida:

The correlation between intraoperative uterine wall thickness measurement and the frequency of gravida was inversely and statistically significant when correlated to age as $\mathrm{R}$ was -0.455 and $p$ value was 0.0001 as shown in Fig. (17).

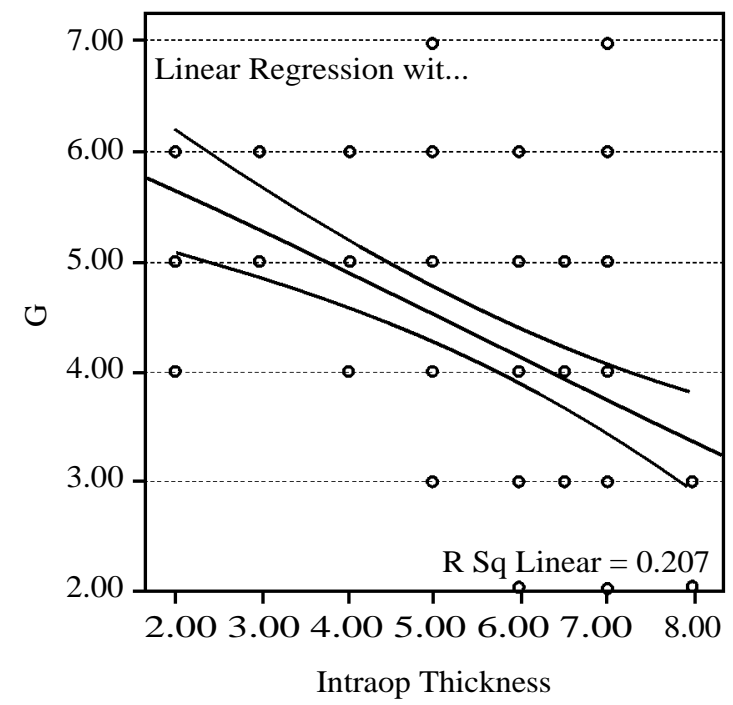

Fig. (17): Correlation between intraoperative uterine wall thickness measurement and the frequency of gravida.

Correlation between intraoperative uterine wall thickness measurement and the frequency of parity:

The correlation between intraoperative uterine wall thickness measurement and the frequency of parity was inversely and statistically significant when correlated to age as $\mathrm{R}$ was -0.379 and $p$ value was 0.0001 as shown in Fig. (18).

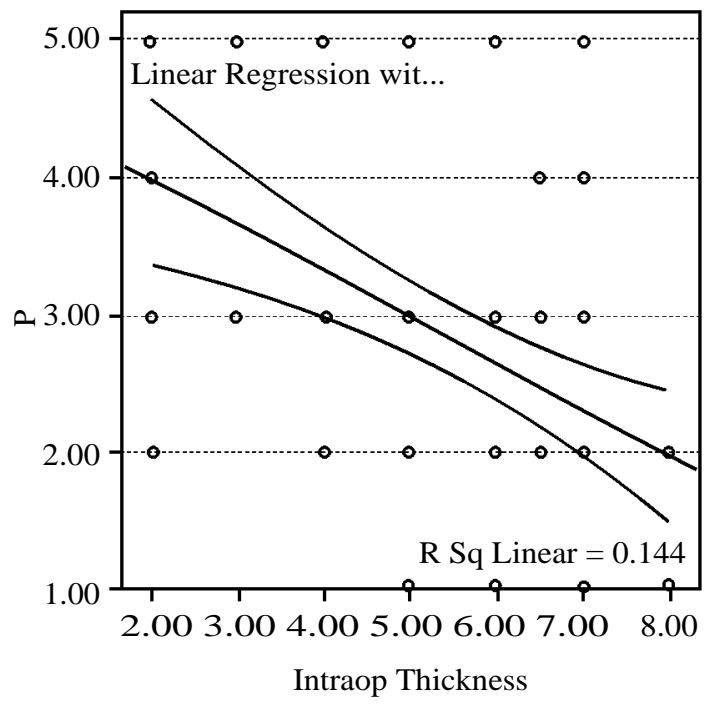

Fig. (18): Correlation between intraoperative uterine wall thickness measurement and the frequency of parity.

Correlation between intraoperative uterine wall thickness measurement and the gestational age:

The correlation between intraoperative uterine wall thickness measurement and the frequency of parity was inversely and statistically significant when correlated to age as $\mathrm{R}$ was -0.63 and $p$-value was 0.0001 as shown in Fig. (19). 


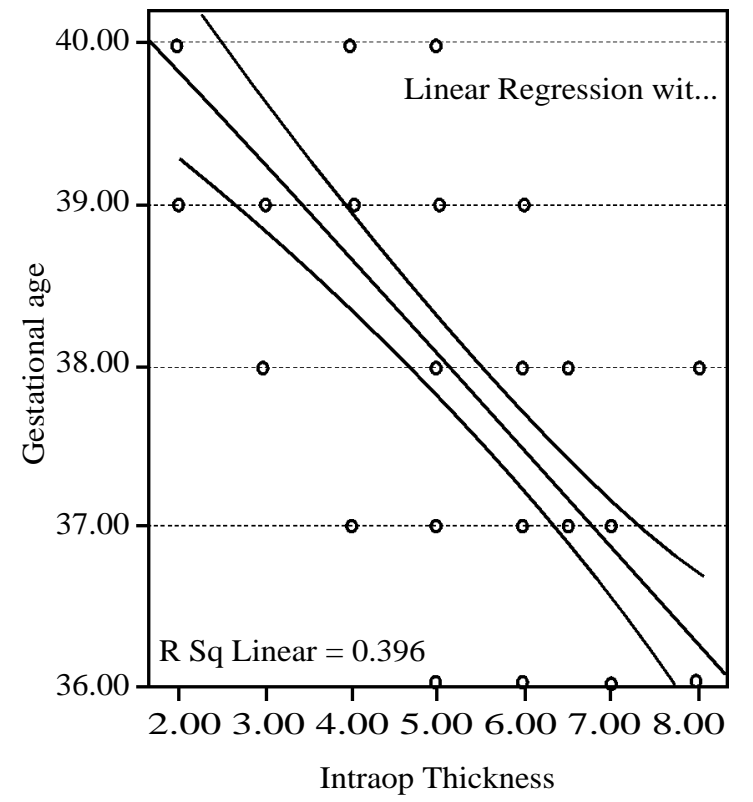

Fig. (19): Correlation between intraoperative uterine wall thickness measurement and the gestational age.

Full anterior wall thickness as measured by 2D at $4.6 \mathrm{~mm}$ was highly predictive having a single CS at sensitivity $100 \%$ and specificity $82 \%$ with AUC of $98.2 \%$ and $p$-value 0.0001 as shown in Table (12) and ROC Fig. (20).

Table (12): Cut off value of full anterior wall thickness as measured by $2 \mathrm{D}$ that could categorize patients having single CS.

AUC Cuf off value $p$-value Sensitivity Specificity

\begin{tabular}{lllll}
\hline .982 & 4.6 & 0.0001 & $100 \%$ & $82 \%$ \\
\hline
\end{tabular}

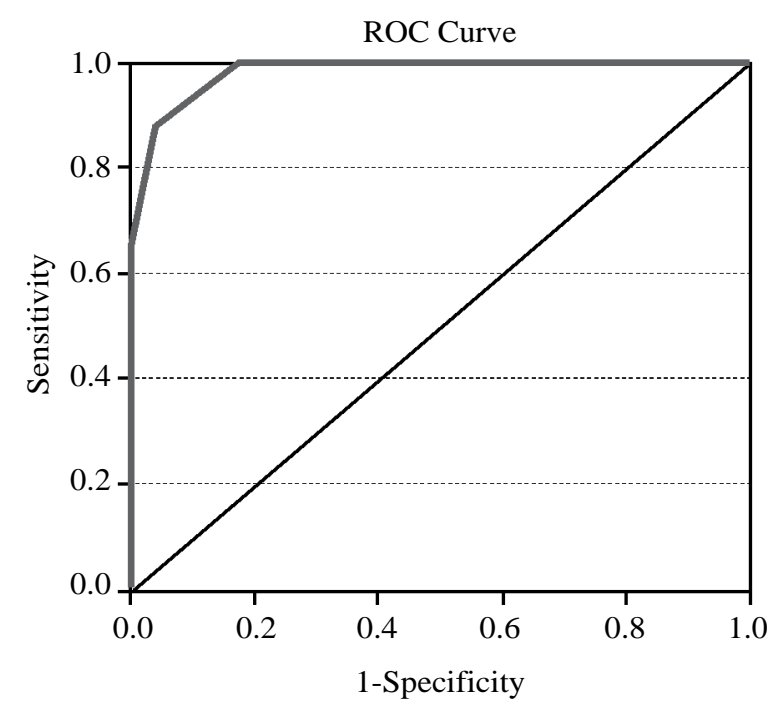

Fig. (20): Cut off value of Full anterior wall thickness as measured by $2 \mathrm{D}$ that could categorize patients having single CS.

\section{Discussion}

Uterine rupture is an uncommon complication of vaginal birth after caesarean (VBAC), the maternal and fetal consequences of which can be serious and potentially life threatening $[\mathbf{1 0 , 1 1 , 1 3 , 1 4 ]}$. Now we are in 2020, there are no reliable methods for predicting the risk of uterine rupture in women attempting VBAC.

Some authors have suggested that sonographic measurement of the lower uterine segment (LUS) may help to select women with the lowest risk of uterine rupture during $[\mathbf{6 , 7 , 8 , 1 5}]$. Although it has been shown that the risk of a scar defect is inversely correlated with LUS thickness, the technique of this measurement remain controversial $[\mathbf{6 , 7 , 8 ]}$.

In a recent systemic review of 12 studies involving 1834 women, Jastrow et al. (2010) [6], confirmed that women with uterine defects had thinner LUS than those without defects. Of the 12 studies included in the review, 7 measured the full LUS thickness, 4 measured the myometrial layer only, and one measured both. However, owing to the heterogeneity of the studies, no ideal cut-off for lower uterine thickness could be recommended for clinical purposes, and the optimal cut-off value varied from 2 to $3 \mathrm{~mm}$ for the full LUS thickness and from 1.4 to $2 \mathrm{~mm}$ for the myometrial layer [6].

In late pregnancy, the LUS appears sonographically as a 2-layered structure comprising the echogenic muscularis and mucosa of the bladder wall, including part of the visceral-parietal peritoneum, and the relatively hypoechoic myometrial layer. The chorioaminiotic membrane and the decidualized endometrial layer cannot usually be seen separate from the myometrium $[\mathbf{8 , 1 5}$. In vertexpresenting fetuses, the presenting part may be firmly applied against the LUS with no amniotic fiuid visible between these 2 structures. Various techniques have been used to measure the LUS, including trans abdominal (TA) and trans vaginal approaches. In some studies $[\mathbf{1 5 , 1 6 , 1 7 ]}$, the entire full LUS thickness was measured, whereas only the inner myometrial layer was included in the measurement in other studies $[\mathbf{8 , 1 8 , 1 9 ]}$. However, almost all studies reported up-to-date use of 2D sonography in measuring the lower uterine segment.

The introduction of 3D volume sonography has enabled multiplanar display of 3D images of LUS, which potentially can improve the reliability of lower uterine segment measurement. One of the best uses of 3D ultra sound is in finding the true center of an object of interest; thus, it could theoratically locate the thinnest area in the US. Inter 
method and inter observer reliability are important when evaluating a clinical test because they ensure reliable measurements when made via another technique or observer, respectively. Previously, only one study addressed the reliability of LUS measurement using 2D and 3D approaches [12]. However that study did not assess the inter method reliability of lower uterine segment measurement using 3D sonography compared with the $2 \mathrm{D}$ approach.

In our study we compared measurements of 2D, 3D of lower uterine segment with the gold standard intra operative measurement. All readings were in agreement that was in concordance with Vincent et al., study in 2011 who compared 2D versus 3D trans abdominal sonography for the measurement of lower uterine segment thickness in women with previous caesarean delivery [20].

In our study the degree of agreement between measurements of LUS full and inner thickness by 2D and 3D sonographic techniques was presented as Pearson correlation co efficient that approximated $100 \%$ and measured around $97 \%$ when correlated to each other. Also both measurements correlated by $82 \%$ to the gold standard measurement intra operatively.

On the other hand; Vincent et al., concluded in their study over 40 pregnant women that compared with the 2D approach, 3D trans abdominal sonography does not seem to improve the reliability of LUS measurement as both methods were adequately correlated to the intra operative measurements with correlation coefficient of 0.82-0.98 respectively. Vincent also preferred 2D measurement of MT which seemed to be most reliable between different observers.

Patients with single CS in our study had a cut off value of $4.6 \mathrm{~mm}$ for lower uterine segments thickness by $2 \mathrm{D}$ with adequate sensitivity and specificity. However, at present, LUS-measuring techniques and the cut-off values used to predict uterine rupture are still controversial. One major concern regarding LUS thickness measurement is the intermethod reliability. Jastrow et al. (2006) [33] reported good correlation between observers regarding full LUS thickness using both TA and transvaginal approaches. However, very few studies have evaluated the inter method reliability of myometrial layer measurement.

It could be believed that 3D sonography can be of potential clinical value in the management of women with previous caesarean delivery. Multi planar display of 3D images enables simultaneous longitudinal, transverse, and coronal views, which allows measurements in a plane perpendicular to the contour of the LUS. This also enables a thorough and complete examination of the entire LUS, which is particularly useful when assessing the risk of uterine rupture in women with unknown previous caesarean scar.

In discordance to our results; the use of 3D sonography for LUS measurement was first studied by Martins et al. (2009) [12], who reported that the technique significantly improved the reliability of trans vaginal measurement of LUS muscular thickness. However, that study evaluated only the intra observer and inter obsever, but not the inter method, reliability of the 2D and 3D measurements [12]. To gain initial experience in the use of 3D sonography for LUS measurement, the authors use only the TA approach to measure both the FT and the inner myometrial layer.

In the present study and Vincent et al., using 3D TA sonography did not seem to improve the accuracy or reliability of LUS measurement compared with the 2D approach. One possible explanation for this finding is that the observers were more familiar with inner myometrial layer measurement because measurement of this layer, rather than the FT, to predict uterine rupture was advocated by the principal author, as reported in his first series of cases [21].

The present study did not clearly demonstrate the benefits of using 3D over 2D sonography for LUS measurement. However, whether the use of the transvaginal 3D approach can improve the reliability of LUS measurement is a potential area for future research. Also, Cheung et al. (2011), compared 2D with 3D ultrasound in measuring LUS, focusing again on inter observer variability and utilizing trans abdominal ultrasound only in measuring LUS. In concordance to us they found that there was no clear benefit of using 3D over 2D ultrasound in measuring LUS [22].

Jastrow and co-workers (2010), in their systematic review of literature have shown that LUS thickness, measured by ultrasound, is a strong predictor of scar dehiscence in women with previous CS. However, the measurement technique is still not standardized and, therefore, ideal cut-off value for prediction of scar dehiscence cannot be recommended [6]. Also, the incidence of uterine scar defects has been varying from $4.9 \%$ [7] to $24 \%$ [23].

Ahmed et al. [28] compared the two methods of measurements 2D vs 3D to predict scar dehis- 
cence in 2015 . The best cut-off value for 2D transvaginal ultrasound as studied by Ahmed et al., in 2015 was $2.0 \mathrm{~mm}$ with AUC of 0.931 with sensitivity of $100 \%$, specificity of $65.71 \%$. The best cut-off value for 3-D transvaginal ultrasound was $1.9 \mathrm{~mm}$ with AUC of 0.974 with sensitivity of $100 \%$, specificity of $87.14 \%$ so trans vaginal 3D measurement of the LUS muscular layer thickness was the best predictor for uterine scar dehiscence.

Ahmed et al., study was the first in the literature to compare 2D and 3D trans abdominal and trans vaginal ultrasound in evaluating LUS and correlates the sonographic findings with the intra operative finding of uterine scar defect. However, in this study, the actual thickness of LUS was not measured intra-operatively and correlated to the sonographic measurement; only the operative finding of scar dehiscence was investigated.

From Ahmed et al., data we could conclude that the clinical difference by both cut off points measured by 2 or $3 \mathrm{D}$ ( $2 \mathrm{~mm}, 1.9 \mathrm{~mm}$ respectively) is not of clinical importance including the sensitivity of $100 \%$ for both giving the clinical attention for sensitivity not specificity for better patient safety.

Hanafy et al., were the first authors to investigate the role of $3 \mathrm{D}$ ultrasound in measuring LUS and its correlation to the intra operative appearance of CS scar. They utilized 3D trans abdominal ultrasound only in their measurement, where the full thickness of the LUS was measured. They concluded that 3D trans abdominal measurement of LUS was very well correlated to the scar appearance [24].

In our study the number of gravida, parity and caesarean sections was significantly and inversely correlated to LUS thickness. In concordance to our study, Ahmed et al study in 2015 has shown that the thickness of the LUS was significantly less in patient with previous more than one CS in comparison with patients with previous one CS. These results agree with the results found by Marasinghe et al., in 2009 [29] where they found that there is strong positive correlation between the number of previous CS and operative findings of scar dehiscence and this implies that number of previous CS is a risk factor for uterine scar dehiscence $(p=0.041)$ [21].

Today, as well as for the last 2 decades in obstetric practice, one of the major topics of debate is decision making in patients with history of previous caesarean delivery [25], The old dictum of "once caesarean always caesarean" [26] is no longer applicable because of the awareness of the obstetricians about the safety of vaginal birth in a scarred uterus as well as the awareness of greater maternal morbidity and mortality in caesarean birth, Attempted vaginal birth after previous caesarean section (VBAC) remains controversial [27].

In our study values of scar thickness less than $4.6 \mathrm{~mm}$ coincided with CS more than one time which hypothetically goes with more liability for wound dehiscence. Regarding trans abdominal ultrasound measurement of the full LUS thickness, Ahmed et al. [28] study suggested a cut-off value of $3.8 \mathrm{~mm}$, and $5 \mathrm{~mm}$ for prediction of uterine scar dehiscence as measured by 2D and 3D ultrasound measurement respectively. By $2 \mathrm{D}$ ultrasound, the cut-off value of $3.8 \mathrm{~mm}$ yielded a sensitivity and specificity of $60 \%$ and $91.46 \%$ respectively with AUC of 0.737 and $95 \%$ confidence interval of 82.3-96.8. These results suggest that the full LUS thickness as measured by 2-D ultra sound is better positive than negative test.

These results are similar to the results and cutoff value suggested by Kushtagi et al. (2001) [30] who performed the largest study on sonographic examination of LUS in scarred uterus. They suggested a cut-off value of $3.5 \mathrm{~mm}$ for scar dehiscence prediction, giving a sensitivity of $88.0 \%$, specificity $73.2 \%$, positive predictive value $11.8 \%$ and a negative predictive value $99.3 \%$. Similar findings were also suggested by Kushtagi et al. (2001) where the cut-off value for scar defects was found to be $3.0 \mathrm{~mm}$.

The use of 3D ultra sound to measure the thinnest part of LUS in Ahmed et al., study has significantly increased the sensitivity, although the specificity has been significantly reduced making the test better negative than positive one.

Fukuda et al. (1988) [31] used a cut-off value of $2 \mathrm{~mm}$ as a potential measure of scar dehiscence. Gotoh et al. (2000) [19] concluded that 74\% of women with a lower uterine segment less than $2 \mathrm{~mm}$ had an incomplete uterine rupture. Asakura et al. (2000) [18] used $1.6 \mathrm{~mm}$ as the cut-off value (they measured the muscularis only) and deduced a $77.8 \%$ sensitivity, $88.6 \%$ specificity, $22.6 \%$ positive predictive value. They assumed that this value was comparable the $3.5 \mathrm{~mm}$ chosen by Rosenberg et al. (1996) [32]. They deduced that prediction of scar dehiscence is not highly reliable and that other factors beside the lower uterine segment thickness may be involved in causing this dehiscence. However, they assumed that owing to the relatively high negative predictive value, a trial of labor 
could be conducted with relative safety if the scar thickness is above the cut-off point.

Sen et al. (2004) [16] used a cut-off value of $2.5 \mathrm{~mm}$ and reported sensitivity, specificity, positive and negative predictive values as follows: $90,9 \%$, $84 \%, 71.4 \%$ and $95.5 \%$ (using abdominal sonography) and $81.8 \%, 84 \%, 69.2 \%$, and $91.3 \%$ (using vaginal sonography). Cheung (2005) [8] have chosen $\mathrm{L} 5 \mathrm{~mm}$ as the best cut-off value and it yielded a sensitivity of $88.9 \%$, a specificity of 59.55 , a positive predictive value of $32.0 \%$, and a negative predictive value of 96.2 in predicting a paper-thin or dehisced LUS.

These figures are nearly the same as Gotoh et al. (2000) [19], who reported a mean scar thickness by TVS at 39 weeks' gestation of $3 \pm 0.7$, but are slightly higher than their counterparts in previous studies. Vincent et al. (2004) [27] reported a scar thickness in the third trimester of $1.9 \pm 1.4 \mathrm{~mm}$ consistent with the results reported by Cheung et al. (2004) [21] reported scar thickness in the third trimester of $2.1 \pm 0.7 \mathrm{~mm}$. On the other hand our figures are lower than those reported by Sen et al. (2004) [16] who stated a mean scar thickness in the third trimester of $3.29 \pm 1.09 \mathrm{~mm}$. Sen et al., reported a mean scar thickness in the third trimester of $3.82 \pm 0.99 \mathrm{~mm}$.

From previous data we summarize that various modalities for assessment of LUS thickness have been proposed to improve reliability of measurements. Non conflicting data which assign inter method agreement. Further studies has to be conducted and focus on the clinical implication for prediction of LUS values which could be safe for vaginal delivery after previous CS rather than inter method differences as variable cut off points were recorded. Further recommendation of development of surgical techniques or evaluation of local growth factors that could decrease chance for wound dehiscence or wall thinning that could be tested by either $2 \mathrm{D}$ or $3 \mathrm{D}$ measurements.

\section{Conclusion:}

Multi caesarean section patients had significant lower value of lower uterine segment thickness by all means of measurements. There was no significant difference regarding habits of medical importance, gestational hypertension, and gestational diabetes mellitus, as regard to incidence in both groups (multi section and single section). Lower uterine segment inner and full diameter measurements were strongly and directly correlated by both 2D and 3D ultrasonography which means the 3D method of assessment added no more value.
Both 2D and 3D method of assessment were correlated to a lower uterine segment measurement intra operatively with a comparable correlation factor. The intra operative thickness was inversely and significantly correlated to age, number of pregnancy, labor and gestational age. 2D assessment of lower uterine segment thickness at 4.6 was significantly predictive of multiple caesarean sections with sensitivity $100 \%$ and specificity $82 \%$ and cut off value of 5.2 was predictive for previous single caesarean section with sensitivity $88 \%$ and specificity $96 \%$.

\section{References}

1- CROWTHER C.A., DODD J.M., HILLER J.E., HASLAM R.R., ROBINSON J.S.: Planned Vaginal Birth or Elective Repeac Caesarean: Patient Preference restricted, Cohort with Nested randomized Trial. PLOS Med., 9: e1001192, 2012.

2- VIKHAREVA O. and VALENTIN L.: Clinical importance of appearance of Caesarean hysterotomy scat at transvaginal ultrasonongraphy in nonpregnantwomen. Obstet. Gynecol., 117: 525-532, 2011.

3- TAHSEEN S. and GRIFFITHS M.: Vaginal birth after two caesarean sections (VBAC-2)-a systematic review with meta-analysis of success rate and adverse outcomes of VBAC-2 versus VBAC-1 and repeat (third) caesarean sections. BJOG: An International Journal of Obstetrics \& Gynaecology, 117 (1): 5-19, 2010.

4- WEN S.W., RUSEN I.D., WALKER M., LISTON R. and KARMER M.S.: Comparison of maternal mortality and morbidity between trial of labor and elective Cesarian section among women with previous Caesarean delivery. Am. J. Obstet. Gynecol., 191: 1263-1269, 2004.

5- LANDON M.B., HAUTH J.C., LEVENO K.J., SPONGE C.Y., LEINDECKER S., VARNER M.W., et al.: Maternal and perinatal outcomes associated with a trial of labour after Caesarean delivery. N. Eng. J. Med., 351: 2581-9, 2004.

6- JASTROW N., CHAILLET N., ROBERGE S., MORENCY A.M., LACASSE Y. and BUJOLD E.: Sonographiclower uterine segment thickness and risk of uterine scar defect: A systematic review. J. Obstet. Gynaecol. Can, 32: 321-327, 2010

7- BUJOLD E., JASTROW N., SIMONEAU J., BRUNET S. and GAUTHIER R.J.: Prediction of complete uterine rupture by sonographic evaluation of the lower uterine segment. Am. J. Obstet. Gynecol., 201: 320.e1-320.e6, 2009.

8- CHEUNG V.Y.: Sonographic measurement of the lower uterine segment thickness in women with previous caesarean section. J. Obstet. Gynecol. Can, 27 (7): 674-81, 2005.

9- JURKOVIC D.: Three-dimensional ultrasound in gynecology: A critical evaluation. Ultrasound Obstet. Gynecol., 19: 109-117, 2002.

10- GROBMAN W.A., LAI Y., LANDON M.B., SPONG C.Y., LEVENO K.J., ROUSE D.J., et al.: Can a prediction model for vaginal birth after caesarean also predict the 
probability of morbidity related to a trial of labor? Am. J. Obstet. Gynecol., 200: 56.e1-56, 2009.

11- GROBMAN W.A., LAI Y., LANDON M.B., SPONG C.Y., LEVENO K.J., ROUSE D.J., et al.: Prediction of uterine rupture associated with attempted vaginal birth after caesarean delivery. Am. J. Obstet. Gynecol., 199: 30, 2008.

12- MARTINS W.P., BARRA D.A., GALLARRETA F.M., NASTRI C.O. and FILHO F.M.: Lower uterine segment thickness measurement in pregnant women with previous Caesarean section: Reliabilityanalysis using two- and three-dimensional transabdominal and transvaginal ultrasound. Ultrasound Obstet. Gynecol., 33: 301-306, 2009.

13- JONES R.O., NAGASHIMA A.W., HARTNETTGOODMAN M.M. and GOODLIN R.C.: Rupture of low transverse caesarean scars during trial of labor. Obstet. Gynecol., 77: 815-817, 1991.

14- LEUNG A.S., LEUNG E.K. and PAUL R.H.: Uterine rupture after previous caesarean delivery: Maternal and fetal consequences. Am. J. Obstet. Gynecol., 169: 945950, 1993.

15- ROZENBERG P., GOFFINET F., PHILLIPPE H.J. and NISAND I. (2005): Ultrasonographic measurement of lower uterine segment to assess risk of defects of scarred uterus. Lancet, 347: 281-284, 1996.

16- SEN S., MALIK S. and SALHAN S.: Ultrasonographic evaluation of lower uterine segment thickness in patients of previous caesarean section. Int. J. Gynecol. Obstet., 87 (3): 215-9, 2004.

17- SUZUKI S., SAWA R., YONEYAMA Y., ASAKURA H. and ARAKI T.: Preoperative diagnosis of dehiscence of LUS in patients with a single previous C.S. Aust. NZJ Obstet. Gynecol., 40 (4): 402-4, 2000.

18- ASAKURA H., NAKAI A., ISHIKAWA G. and ARAKI T.: Prediction of uterine scar dehiscence by measuring lower uterine segment thickness prior to onset of labour. J. Nibbon Medical School, 67: 5-10, 2000.

19- GOTOH H., MASUZAKI H., YOSHIDA A., YOSHIMURA S., MIYAMURA T. and ISHIMARU T.: Predicting incomplete uterine rupture with vaginal sonography during the late second trimester in women with prior caesarean. Obstet. Gynecol., 95: 596-600, 2000.

20- VINCENT Y.T., CHEUNGE FANG YANG and KWOKYIN LEUNG: 2D versus 3D transabdominal sonography for the measurement of lower uterine segment thickness in women with previous caesarean delivery, doi: 10.1016/j.ijgo.2011.03.021, 2011.

21- CHEUNG V.Y., CONSTANTINESCU O.C. and AHLUWALIA B.S.: Sonographic evaluation of the lower uterine segment in patients with previous caesarean delivery. J. Ultrasound Med., 23 (11): pp. 1441-1447, 2004.

22- CHEUNG V.Y., YANG F. and LEUNG K.Y.: 2 D versus 3D transabdominal sonography for the measurement of lower uterine segment thickness in women with previous caesarean delivery. Int. J. Gynaecol. Obstet., 114: 234237, 2011.

23- ABDEL BASET M., AL-MOGHAZI D.A., HAMDY M.T. and MOHAMMED E.M.: Ultrasonographic evaluation of lower uterine segment thickness in pregnant women with previous caesarean section. Middle East Fertility Society Journal, 15 (3): 188-93, 2010.

24- HANAFY A. and ABDELMALEK K.: Three Dimensional Ultrasound Assessment of CS Scar: A Cross Sectional Study. Kasralaini J. Obstet. Gynecol., 2, 2: 16, 2011.

25- QURESHI I.A., ULLAH H., AKRAM M.H., ASHFAQ S. and NAYYAR S.: Transvaginal versus transabdominal sonography in the evaluation of pelvic pathology. J. Coll. physicians Surge., 14 (7): 390-3, 2004.

26- CRAIGIN E.: Conservation in obstetrics. N Y Med. J., 1: 104, 1916.

27- VINCENT Y.T. CHUNG, BIRINDER S. and OANA S.: Sonographic evaluation of the LUS in patients with previous C.S. J. Ultrasound Med., 23: 1441-1447, 2004.

28- AHMED M., GEBRIL A.H. and ABDELHAFEZ A.: 2D and $3 \mathrm{D}$ ultrasound assessment of caesarean section scars and its correlation to intraoperative findings. Uterus \& Ovary, 2: 1-7, 2015.

29- MARASINGHE J.P., SENANAYAKE H., RANDENIYA C. and SENEVIRATNE H.R.: Comparison of transabdominal versus transvaginal ultrasound to measure thickness of the lower uterine segment at term. Int. J. Gynecol. Obstet., 107: 140-142, 2009.

30- KUSHTAGI P. and GAREPALLI S.: Sonographic assessment of lower uterine segment at term in women with previous Caesarean delivery. Arch. Gynecol. Obstet., 283: 455-459, 2001

31- FUKUDA M.: Examination of previous C.S. scars by ultrasound. Arch. Gynecol. Obstet., 243: 221, 1988.

32- ROSENBERG P., GOFFINET F. and PHILLIPPE H.J.: Ultrasonographic measurement of lower uterine segment to assess risk of defects of scarred uterus. Lancet, 347 : 281-84, 1996.

33- JASTROW N., ANTONELLI E., ROBYR R., IRION O. and BOULVAIN M.: Inter- and intraobserver variability in sonographic measurement of the lower uterine segment after a previous Caesarean section. Ultrasound Obstet. Gynecol., 27 (4): 420-424, 2006. 


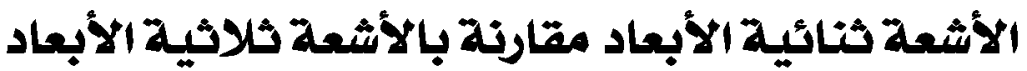

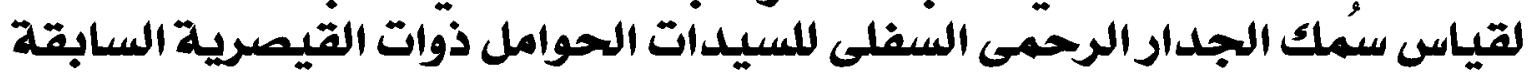

تعد الولادة القيصرية من العمليات الاكثر شيوعاً التى تجرى بواسطة أطباء النساء والتوليد، وبسبب المخاطر والمضاعاعفات المبات التى تسبيها

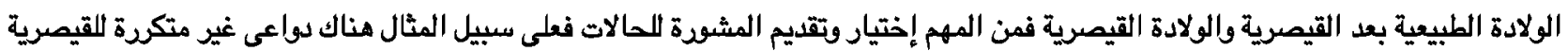

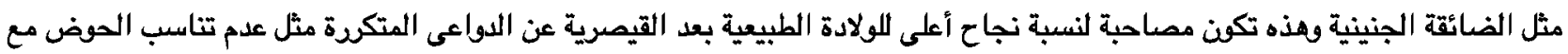

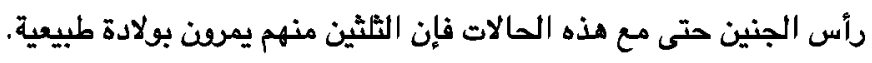

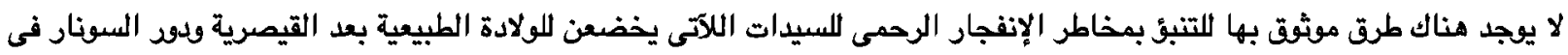

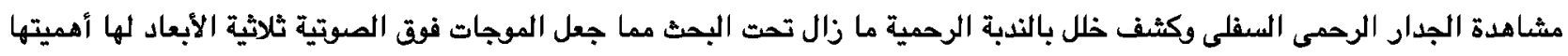
الإكلينيكية فى علاج السيدات ذوات الولادة القيصرية السابقة من خلال عرض المستويات المتعددة للأشعة فى مقاطع طولية وعرضية وتاجية. الهدف من الدراسة: هو تقييم الطرق والمشاهدة المؤكدة اللموجات فوق الصوتية ثنائية وثلاثية الأبعاد لقياس سماكة الجدار الرحمى السفلى. هذه الدراسة تضمنت مائة سيدة حامل سيجرين لهم قيصرية إختيارية فى الجدار الرحمى السفلى عدد الحالات الخاضعة اللدراسة قسمت إلى مجموعتين: • • المجموعة الأولى: • • مالة ذوات قيصرية سابقة واحدة.

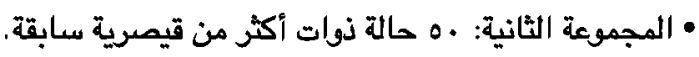

$$
\text { وتضمنت الدراسة: }
$$

• أى حالة أجرى لها قيصرية سابقة ومكتملة الحمل من الأسبوع لج إلى وج". • هذه المريضة سيجرى لها قيصرية إختيارية. واستبعدت الدراسة:

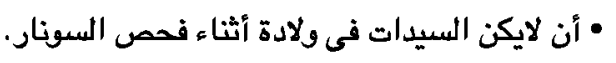
• الحمل فى أكثر من جنين. • • تغيير فى حجم السائل المحيط بالجنين. • مشيمة متقدمة. كل فخوصات السونار جرت لقياس: سماكة الجدار الرحمى السفلى بالكامل والتى ستقاس من الطبقة العضلية والمخاطية للمثانة إلى الأغثية المحيطة بالجنين مع وجود الطبقة العضلية للرحم بينهم.

$$
\text { كما تم تياس الطبقة العضلية للرحم عند أقل سمك وعمودى القوام الجدار الرحمى السفلى. }
$$

ولقد تم تسجيل النتائج فى جداول وأشكال بيانية توضح قياس سمك ندبة الرحم الناتجة عن العملية القيصرية باستخدام الموجات فوق

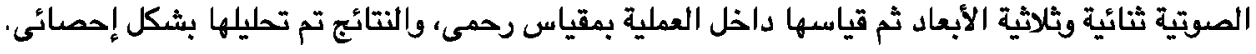

